\title{
Energetics and Dynamics of Subtropical Australian East Coast Cyclones: Two Contrasting Cases
}

\author{
LEONE CAVICCHIA \\ School of Earth Sciences, University of Melbourne, Melbourne, Australia \\ ANDREW DOWDY \\ Bureau of Meteorology, Melbourne, Australia \\ KEVIN WALSH \\ School of Earth Sciences, University of Melbourne, Melbourne, Australia
}

(Manuscript received 27 October 2017, in final form 13 March 2018)

\begin{abstract}
The subtropical east coast region of Australia is characterized by the frequent occurrence of low pressure systems, known as east coast lows (ECLs). The more intense ECLs can cause severe damage and disruptions to this region. While the term "east coast low" refers to a broad classification of events, it has been argued that different ECLs can have substantial differences in their nature, being dominated by baroclinic and barotropic processes in different degrees. Here we reexamine two well-known historical ECL case studies under this perspective: the Duck storm of March 2001 and the Pasha Bulker storm of June 2007. Exploiting the cyclone phase space analysis to study the storms' full three-dimensional structure, we show that one storm has features similar to a typical extratropical frontal cyclone, while the other has hybrid tropical-extratropical characteristics. Furthermore, we examine the energetics of the atmosphere in a limited area including both systems for the ECL occurrence times, and show that the two cyclones are associated with different signatures in the energy conversion terms. We argue that the systematic use of the phase space and energetics diagnostics can form the basis for a physically based classification of ECLs, which is important to advance the understanding of ECL risk in a changing climate.
\end{abstract}

\section{Introduction}

The subtropical east coast of Australia is often affected by low pressure systems that can cause highimpact weather. Such systems are collectively known as east coast lows (ECLs). All cyclones crossing the area are generally considered ECLs irrespective of whether they are midlatitude cyclones entering the region from the southern boundary, transitioning tropical cyclones, or are formed locally, and irrespective of the mechanisms responsible for their formation.

Building upon some of the earlier studies of ECL occurrence (Holland et al. 1987; Hopkins and Holland 1997), significant progress in the field has been achieved during the last decade. Speer et al. (2009) compiled a

\footnotetext{
Corresponding author: Leone Cavicchia, leone.cavicchia@unimelb. edu.au
}

climatology for the years 1970-2006 based on subjective identification of ECLs in pressure charts, which is widely used as an observational reference in further ECL studies. To overcome the limitations in terms of homogeneity and extendibility of subjective detection, different automated methods to detect ECLs have subsequently been used to derive updated storm climatologies, such as the works of Pepler and CouttsSmith (2013) based on the Laplacian method developed in Murray and Simmonds (1991), Browning and Goodwin (2013) based on pressure gradients, and Dowdy et al. (2011, 2013a) based on upper-level vorticity. These ECL detection methods have been systematically compared in Pepler et al. (2015), concluding that different approaches are better suited to reproducing different aspects of ECL climatology. Di Luca et al. (2015) compared the use of various reanalysis datasets in producing ECL climatologies, with the aim of singling out the effect of resolution. 
They concluded that while all of the modern highresolution reanalyses yield similar results for the larger ECLs, their performance differs when subsynoptic-scale low pressure systems are considered. In addition, few studies have attempted to systematically classify ECLs into different categories. Browning and Goodwin (2013) proposed a classification of ECLs in five categories based on their region of origin and direction of propagation, but did not examine any potential differences in structure or development mechanisms.

Dowdy et al. (2013b) investigated the changes in the frequency of ECLs in global climate model projections, finding a robust decreasing trend for the occurrence of ECLs in the cold season associated with a lower frequency of upper cutoff lows over eastern Australia due to increasing atmospheric greenhouse gas concentrations. Pepler et al. (2016) also found indications of fewer ECLs in regional climate models future projections during the cooler months of the year, as well as a possible increase in ECL events in the warm season. It is not known so far whether the relative proportion of different ECL types will remain the same or change in future climate conditions with respect to the relative influences of baroclinic and barotropic processes, including how this could influence their regional distribution, intensity and associated impacts.

The purpose of this paper is to establish a simple and effective methodology aimed at diagnosing the relative contributions from the baroclinic and barotropic storm formation and intensification pathways. This will allow a better understanding of the environment that favors their formation in the current climate, and how that environment could change (see e.g., Cavicchia et al. 2014b).

All the aforementioned studies are based on the use of a single pressure layer, be it the surface or some upper geopotential layer. On the other hand, it has been shown (Hart 2003) that the analysis of the complete vertical structure of the cyclones is needed if they are to be classified according to the physical processes leading to their formation and intensification. There are clear indications from previous studies that the broad ECL set includes both cyclones showing typical midlatitude storm features as well as hybrid storms, which share the characteristics of both tropical and extratropical cyclones. Hybrid cyclones have been shown to occur globally in a latitude belt between the tropics and the extratropics (Yanase et al. 2014), with the Tasman Sea being one of the hotspot regions for the occurrence of this type of storm. Several studies have documented the occurrence of hybrid storms in different regions, such as the southwestern Atlantic (Evans and Braun 2012; Gozzo et al. 2014), the northern Atlantic (Guishard et al. 2009; Mauk and Hobgood 2012), the central North
Pacific (Otkin and Martin 2004; Caruso and Businger 2006), and the Mediterranean Sea (Cavicchia et al. 2014a; Miglietta et al. 2013a; Walsh et al. 2014). The occurrence of a mix of mechanisms responsible for the formation of subtropical systems in different regions of the world motivates an analysis of mechanisms in ECL development off the subtropical east coast of Australia.

Here we establish an approach aimed at a physically based classification of ECLs, based on the analysis of storm three-dimensional structure (presence of a warm/ cold core and vertical symmetry) and on the cyclone energetics. To do so, we revisit two well-known historical ECL cases using this approach, and show that they are representative cases of different sectors of the ECL spectrum. We argue that such a classification, when applied systematically to automatically detected storms in multidecadal datasets, has the potential to advance our understanding of the occurrence and intensification of ECLs and possibly of subtropical cyclones in diverse regions worldwide. Moreover, such an approach could prove to be useful in the context of the analysis of projections of future occurrence of storms.

The two cases analyzed here are the "Duck" cyclone that occurred in March 2001 and the "Pasha Bulker" storm of June 2007. The Duck cyclone (Qi et al. 2006; Pezza et al. 2014) took its name according to Garde et al. (2010) from a phrase appearing in an early debate on the storm's nature. The observation of several unusual characteristics of this storm prompted a debate in the meteorological community, and the hypothesis that it might be a tropical cyclone was advanced, with Pezza et al. (2014) describing it as a "rare hybrid subtropical cyclone" with its formation based on a combined influence from an existing tropical cyclone and a persistent midlatitude blocking high pressure system. The Pasha Bulker ECL (Mills et al. 2010; Chambers et al. 2014) is named after the bulk carrier bearing the same name that was beached by the storm on the Newcastle coast on the morning of 8 June 2007. It was one of the largest disasters in Australia in terms of insured losses.

The analysis presented here also includes a consideration of convective processes, based on lightning data as an observations-based proxy for the occurrence of deep convection and thunderstorm activity (Rakov and Uman 2003), noting that previous studies have suggested a link between ECLs and thunderstorm activity including for the Pasha Bulker case (Chambers et al. 2015; Dowdy and Kuleshov 2014). Lightning in the regions shown is not claimed to be associated with the cyclones. The lightning observations are rather used to help analyze the evolution of the phase space and energetics parameters, providing spatial and temporal information at various stages of the storms lifetimes in relation to the 
occurrence of convective processes, noting that convection can influence environmental conditions associated with cyclogenesis (e.g., Raymond and Sessions 2007). In the case of tropical cyclones, it was shown that the strongest lightning activity is found in the phase preceding cyclone intensification (Price et al. 2009). A similar behavior has been observed for some cases of subtropical storms (Miglietta et al. 2013b).

The paper is structured as follows. In section 2 the datasets employed in this work are described. The methodology used to carry out the analysis is reviewed, and links to the relevant literature for a more detailed discussion provided. In section 3 the main results of this work are shown. First, the analysis of the evolution of the storms based on sea level pressure and geopotential fields is presented. The analysis of cyclone phase space and energetics parameters is then presented and discussed. In addition, the impact of the choice of atmospheric data on the aforementioned analysis is shown. Finally, in section 4 the key findings of this work are summarized, and some recommendations for further work are given.

\section{Data and methods}

\section{a. Datasets}

The main source of atmospheric data used in this work is 6-hourly fields from the ERA-Interim reanalysis (Dee et al. 2011). Ranging from 1979 to present, ERA-Interim provides atmospheric fields with a horizontal resolution of $0.75^{\circ}$ at the surface and on 37 vertical pressure levels up to $1 \mathrm{hPa}$. Pepler et al. (2018) showed that ERAInterim is one of the most skilled among modern highresolution reanalysis datasets in reproducing ECL properties.

While the role of resolution and the choice of dataset have been extensively investigated in the context of surface-based ECL studies, this type of analysis has not been performed so far for the full vertical extent of the cyclones. To assess whether the analysis of cyclone phase and energetics is quantitatively robust, or whether it shows a sensitivity to the data source, we compare the results obtained from ERA-Interim with the same analysis performed using a different data source. The product chosen for the comparison is the New South Wales (NSW) and Australian Capital Territory (ACT) Regional Climate Modeling Project (NARCliM; Evans et al. 2014). Designed to produce high-resolution climate change scenarios for southeastern Australia, NARCliM is obtained by dynamically downscaling the atmospheric fields from large-scale reanalysis and global climate models. The dataset is available on a domain covering all Australia with a horizontal resolution of approximately $50 \mathrm{~km}$, and on a second nested domain centered on the southeast coast of Australia with a horizontal resolution of about $10 \mathrm{~km}$. In the evaluation runs the downscaling is driven by the NCEP-NCAR reanalysis (Kalnay et al. 1996), and initialized in 1950. The dynamical downscaling is performed with the Weather Research and Forecasting (WRF) Model (Michalakes et al. 2001), implemented in three versions where different choices for the physical parameterizations are adopted. In this work we will be using data produced with the model version $\mathrm{R} 2$ at $50-\mathrm{km}$ horizontal resolution, which has been shown to have the best performance in reproducing ECLs, in particular in representing the spatial distribution of ECLs across different seasons (Di Luca et al. 2016).

Lightning data were obtained from the commercial provider Global Position and Tracking System Pty. Ltd. Australia (GPATS). The data are based on the time of arrival of the electromagnetic disturbance propagating away from the lightning discharge as recorded at a network of ground-based radio receivers (Cummins and Murphy 2009) and contain information about the time and location of individual lightning strokes, including both cloud-to-ground as well as cloud-to-cloud lightning strokes. The detection efficiency of the GPATS system (Kuleshov et al. 2006) varies temporally (e.g., due to ongoing changes in the hardware and software used by the commercial provider of these data) as well as spatially (e.g., due to proximity to receivers). Consequently, the number of lightning strokes recorded by the GPATS system is used throughout this study as a lower bound measure of the total lightning strokes that occurred. Moreover, because of the aforementioned inhomogeneities, care has to be taken when comparing the number of lightning strokes recorded for the different storms. Therefore, lightning is used in this study only as a general indicator of convective activity.

\section{b. Methods}

The cyclone phase space method was originally developed by Hart (2003) in the context of the study of extratropical transitions of tropical cyclones. It is based on the underlying idea that a limited set of optimal parameters can be defined and used to classify cyclones according to the main features within their vertical structure. In particular, cyclones driven by barotropic processes-such as tropical cyclones-are characterized by a vertically symmetric structure and a warm core, whereas cyclones driven by baroclinic processes-such as frontal midlatitude systems - are typically vertically tilted and cold cored. In addition to transitioning cyclones, hybrid cyclones, showing characteristics of both 
the aforementioned categories for most of their lifetime, have been observed in different regions in recent decades (Yanase et al. 2014). Such observations suggest that the cyclone spectrum is a continuum in which purely barotropic or baroclinic systems are the extremes. The phase space concept accommodates such an extension of cyclone classification beyond the binary tropicalextratropical paradigm.

The cyclone phase space is based on three parameters:

-The $B$ parameter is defined as the difference between the thickness of the $600-900-\mathrm{hPa}$ layer, averaged within two circles of $500-\mathrm{km}$ radius, respectively, to the left and to the right with respect to the storm motion direction:

$$
B=\left(\overline{\left.Z\right|_{600 \mathrm{hPa}}-\left.Z\right|_{900 \mathrm{hPa}}}\right)_{L}-\left(\overline{\left.Z\right|_{600 \mathrm{hPa}}-\left.Z\right|_{900 \mathrm{hPa}}}\right)_{R} .
$$

It is used to differentiate vertically symmetrical $(B<10)$ and tilted $(B>10)$ cyclones.

-The lower atmosphere thermal wind, $-V_{T}^{L}$, is defined as the vertical derivative between 900 and $600 \mathrm{hPa}$ of the height gradient in a $500-\mathrm{km}$ radius:

$$
-V_{T}^{L}=\left.\frac{\left.\partial\left(Z_{\max }-Z_{\min }\right)\right|_{500 \mathrm{~km}}}{\partial \ln p}\right|_{600 \mathrm{hPa}} ^{900 \mathrm{~Pa} a},
$$

where the vertical derivative is calculated used a linear regression fit of the height difference. It indicates whether the interior of the lower troposphere cyclone circulation is colder (cold-core cyclone, $-V_{T}^{L}<0$ ) or warmer (warm-core cyclone, $-V_{T}^{L}>0$ ) than the surrounding atmosphere.

- The upper atmosphere thermal wind, $-V_{T}^{U}$, is the same as $-V_{T}^{L}$, but it is calculated in the upper layers of the troposphere, between 600 and $300 \mathrm{hPa}$.

The original value of $500 \mathrm{~km}$ for the calculation radius has been chosen here because of the relatively large scale of the studied storms. Sensitivity studies have shown on the other hand that smaller values of the radius might be more suitable when focusing on smallerscale cyclones (Miglietta et al. 2013a). Slightly different ranges of threshold values have been adopted in works focusing on different regions. We will make use here of the most widely used values, and refer to a cyclone respectively as baroclinic when it is associated with $B>10,-V_{T}^{L}<0$, and $-V_{T}^{U}<0$; barotropic if $B<10,-V_{T}^{L}>0$, and $-V_{T}^{U}>0$; and hybrid if the signs of $-V_{T}^{L}$ and $-V_{T}^{U}$ are opposite. As a side remark, some ambiguity in the use of the terminology might sometimes arise in the literature as the terms "hybrid" and "subtropical" cyclones are sometimes referred to with the same meaning. In the present work, we shall use the term subtropical cyclone when a merely geographical characterization is implied, whereas we will refer to a hybrid cyclone to indicate a classification based on physical features of the storm.

The energy cycle will be used as an additional indicator of the mechanisms of storm development. The concept of partitioning the atmosphere energetics into different components and analyzing their evolution in terms of the mutual conversion of such components dates back to Lorenz (1955). A schematic view of the energy cycle is shown in Fig. 1. The energy content of the atmosphere is divided in four components: the zonal available potential energy $A_{Z}$, the zonal kinetic energy $K_{Z}$, the eddy available potential energy $A_{E}$, and the eddy kinetic energy $K_{E}$. The conversion terms between different energy forms are also considered: $C_{A}$ (conversion between $A_{Z}$ and $A_{E}$ ), $C_{Z}$ (conversion between $A_{Z}$ and $K_{Z}$ ), $C_{K}$ (conversion between $K_{Z}$ and $K_{E}$ ), and $C_{E}$ (conversion between $A_{E}$ and $\left.K_{E}\right)$. When the whole atmosphere is considered, the energetics can be fully described considering the two generation terms for zonal $\left(G_{Z}\right)$ and eddy $\left(G_{E}\right)$ available potential energies, the two dissipation terms for zonal $\left(D_{Z}\right)$ and eddy $\left(D_{E}\right)$ kinetic energies. The energy cycle concept can also be applied to a limited domain within the atmosphere. In this case, additional terms have to be considered in the energy cycle, for each of the four components, related to the energy transport at the lateral boundaries of the domain $\left(B A_{Z}, B A_{E}, B K_{Z}\right.$, and $\left.B K_{E}\right)$. Previous studies showed that useful information on the cyclone energetics can be inferred by studying the temporal evolution of the area-averaged and vertically integrated energy and conversion terms (Black and Pezza 2013; Pezza et al. 2014). The analysis performed will therefore focus on such terms, while the generation, dissipation, and boundary terms, that are generally one order of magnitude smaller, will not be shown in the following. In particular, the processes driving the different cyclone formation and intensification pathways are expected to be visible in the energy conversion terms. Baroclinic processes contribute to the terms $C_{A}, C_{E}$, and $C_{Z}$, all associated with horizontal temperature gradients in the atmosphere and the transport of sensible heat. Barotropic processes, on the other hand, contribute to the term $C_{K}$, which is linked to momentum transport (Boer and Lambert 2008).

The different terms entering in the energy cycle are obtained following the approach described in Veiga and Ambrizzi (2013) and references therein, where the full formulas used in the computation are also reported. In the present study the wind, temperature, and vertical velocity fields from ERA-Interim are used for the calculation, on vertical pressure levels between 1000 and $100 \mathrm{hPa}$. 


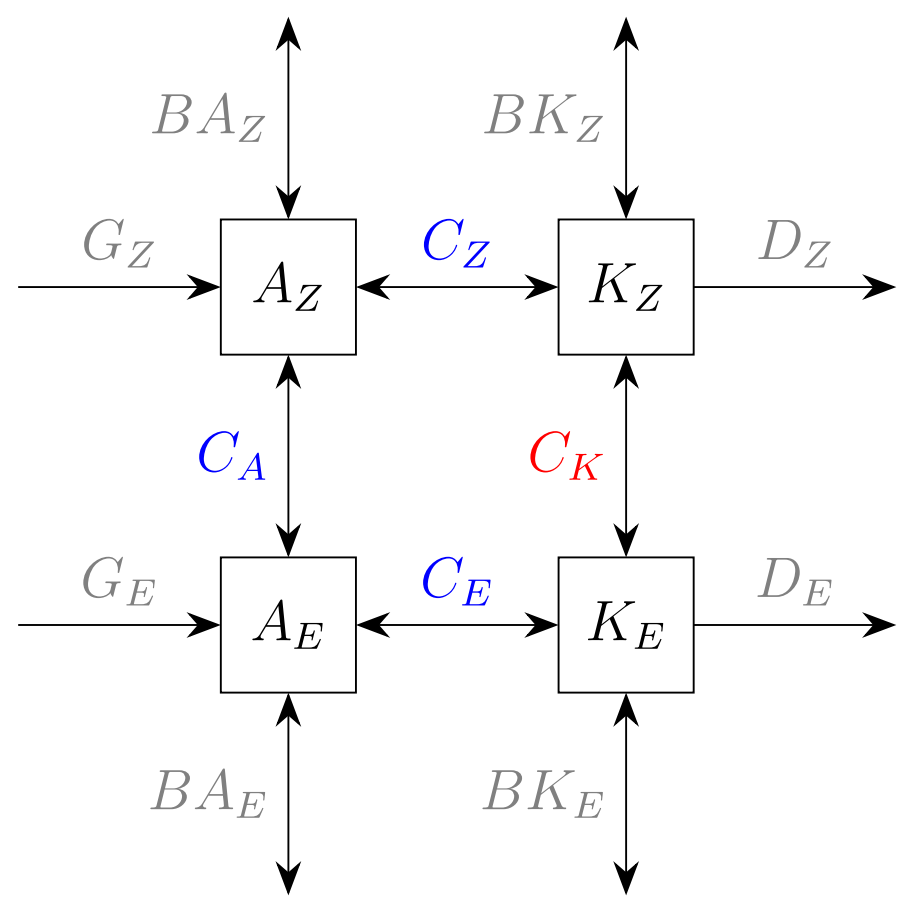

\begin{tabular}{|c|c|}
\hline Energy terms & $A_{E}, A_{Z}, K_{E}, K_{Z}$ \\
\hline Conversion terms & $C_{Z}, C_{E}, C_{A}, C_{K}$ \\
\hline Generation terms & $G_{Z}, G_{E}$ \\
\hline Dissipation terms & $D_{Z}, D_{E}$ \\
\hline Boundary terms & $B A_{E}, B A_{Z}, B K_{E}, B K_{Z}$ \\
\hline
\end{tabular}

FIG. 1. Schematic representation of the different terms in the energy cycle as described in the text. Adapted from Veiga and Ambrizzi (2013).

The limited-area energetics analysis has been shown to provide useful insight into the study of cyclones. When the calculation domain is chosen in such a way that the cyclone is the only relevant large-scale feature within the box, the evolution of the different conversion terms can provide information on the nature of the processes associated with the storm formation and intensification. The information this technique provides is complementary to that derived from phase space diagrams: while the phase space analysis focuses on the internal structure of the storm, the energetics does not directly describe the cyclone but rather the processes taking place in the surrounding environment that can support its intensification by providing the needed energy.

A number of studies have used the limited-area energy cycle to investigate different types of cyclones. Veiga et al. (2008) investigated the exceptional occurrence of a hurricane in the southern Atlantic (Hurricane Catarina in 2004), showing how it developed from a hybrid cyclone through the tropical transition mechanism (Davis and Bosart 2003, 2004; McTaggart-Cowan et al. 2008). Hybrid cyclones are indeed a common feature in the subtropical part of the southern Atlantic (Dias Pinto et al. 2013). Dias Pinto and Da Rocha (2011) analyzed three cases of subtropical cyclones off the eastern coast of South America, classifying them as baroclinic or hybrid storms according to the phase space parameters. They found that the energetics signatures also differ, drawing a consistent picture of the different processes underlying cyclone formation and intensification. Black and Pezza (2013) analyzed a large sample of midlatitude storms and found that the subset of cyclones undergoing explosive intensification shows a signature in the large-scale energetics associated with the baroclinic cycle that is universal 
Duck

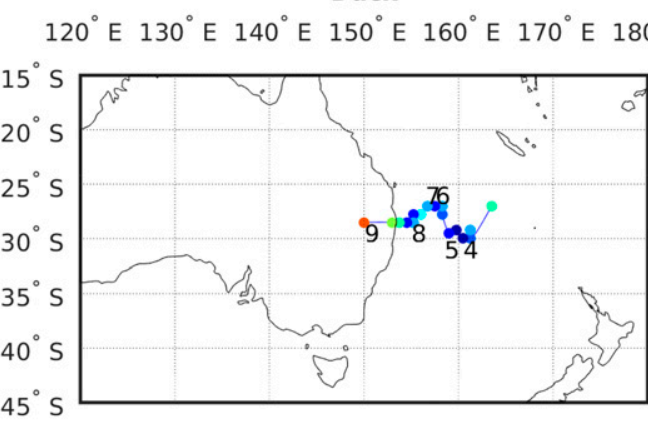

Pasha Bulker

$120^{\circ} \mathrm{E} 130^{\circ} \mathrm{E} 140^{\circ} \mathrm{E} 150^{\circ} \mathrm{E} 160^{\circ} \mathrm{E} 170^{\circ} \mathrm{E} 180^{\circ}$

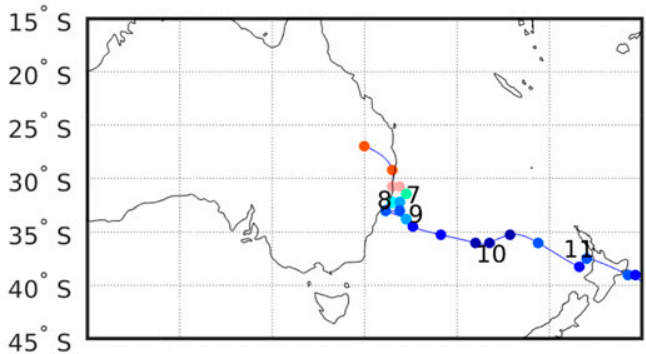

hPa

FIG. 2. Tracks of (left) the Duck and (right) the Pasha Bulker east coast lows. Colored circles represent the values of mean sea level pressure minima as shown in the color scale. Text labels indicate the dates (for 0000 UTC times) in the month of March 2001 for the Duck and June 2007 for the Pasha Bulker.

across different ocean basins and is not present in the storms that have a normal deepening rate. The energy cycle was analyzed for the first time for a case of an Australian ECL by Pezza et al. (2014). Here we extend their energetics analysis by investigating how the comparison of the energy cycle terms computed over a common domain (selected with a view to future systematic climatological applications) can be used to differentiate the mechanisms driving the development of different types of ECLs.

\section{Results}

\section{a. Synoptic analysis}

The tracks of the two storms, obtained by minima of the ERA-Interim mean sea level pressure field at consecutive 6-hourly time steps, are shown in Fig. 2. The ECLs are tracked at all times where a closed sea level pressure minimum associated with the cyclone is present. The two storms differ in their average direction of propagation. The Pasha Bulker showed a slow propagation phase in the first stage of its development (6-8 June), when most of the impact on the coastal areas was produced, followed by a second phase characterized by an eastward movement (9-11 June). The Duck, on the other hand, developed over the Tasman Sea (3-4 March), moving subsequently westward toward the Australian east coast, where it made landfall and dissipated (on 8 March). The maximum intensity in terms of minimum mean sea level pressure for the Duck was registered shortly after the storm's genesis, whereas the Pasha Bulker kept deepening and reached its maximum intensity at a later stage of its evolution. However, for the Pasha Bulker the largest deepening rate of the surface pressure minimum is also observed in the first stages of its intensification. The pressure drop in the later stages, on the other hand, could be associated with the spatial gradient of the pressure field (i.e., lower background pressures as the Pasha Bulker storm tracked poleward in its later stages).

More differences emerge when focusing on the evolution of the mean sea level pressure and 500-hPa geopotential patterns (Figs. 3 and 4). The formation and intensification of both cyclones are associated with a trough/cutoff feature in the upper atmosphere. In the case of the Duck, the sea level pressure minimum develops at a location coincident with the 500-hPa cutoff low. The surface and upper-level minima remain collocated for most of the cyclone lifetime. In the case of the Pasha Bulker, on the other hand, when the closed surface isobars first appear, they are displaced a few hundred kilometers with respect to the 500-hPa height minimum. Only about $48 \mathrm{~h}$ after the storm formation, do the two features become vertically aligned. Such a difference in the evolution of the two storms is consistent with the different observed deepening previously described.

Differences between the two storms are also apparent from the lightning activity (Fig. 5), indicating much stronger convection in the vicinity of the Pasha Bulker storm (e.g., many thousands of lightning strokes) than for the Duck (e.g., fewer than a thousand lightning strokes). However, in both cases it is clear that the broadscale conditions that the storms develop in include regions of thermodynamic instability in the surrounding environment [as evident from the lightning activity as a proxy for deep and intense convection (Rakov and Uman 2003)]. 

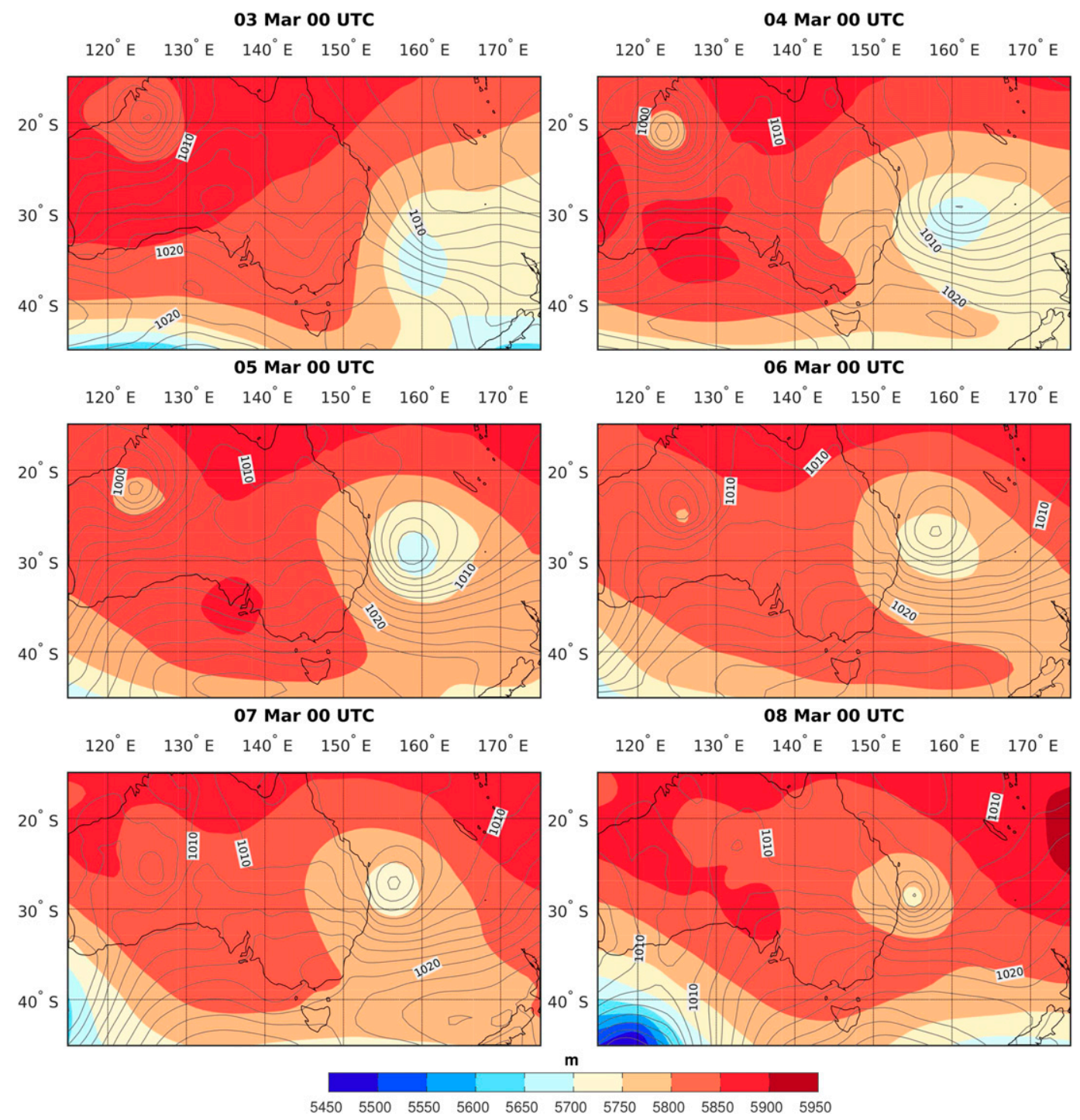

FIG. 3. Snapshots of mean sea level pressure (contours, 2-hPa spacing) and 500-hPa geopotential height (shaded, values as in the color scale) for the Duck. UTC date and time are indicated above each panel.

For the Duck, the most intense lightning is observed during the period around landfall, in the last hours of 8 March. For the Pasha Bulker case, the majority of the lightning activity occurs during the intensification phase on 8 and 9 June (see also the time series in Fig. 9).

\section{b. Phase space and energetics analysis}

The phase space parameters for the Duck and Pasha Bulker storms are shown in Fig. 6. The Duck is characterized for most of its lifetime by a structure with a warm core in the lower troposphere and a cold core in the upper troposphere: this is the feature that defines a hybrid cyclone. The $B$ parameter is mostly smaller than 10 , indicating vertical symmetry. The Pasha Bulker, on the other hand, is characterized by a cold core in both the lower and higher troposphere, indicating a thermal structure similar to that of baroclinic storms. The $B$ parameter, however, does not have a coherent pattern, oscillating between values larger and smaller than 10. This can be because during the stationary phase, the direction of propagation of the cyclone is not well defined. On the other hand, it gives a potential indication that the cyclone life cycle may not be solely baroclinic. Moreover, it is worth noticing that the phase of maximum deepening of the storm is associated with the only positive values of $-V_{T}^{L}$, indicating a warm core in the lower troposphere.

Figure 7 shows the relationship between the phase space parameters and the lightning activity for the two storms. The lower-level thermal wind parameter $-V_{T}^{L}$ shows some 


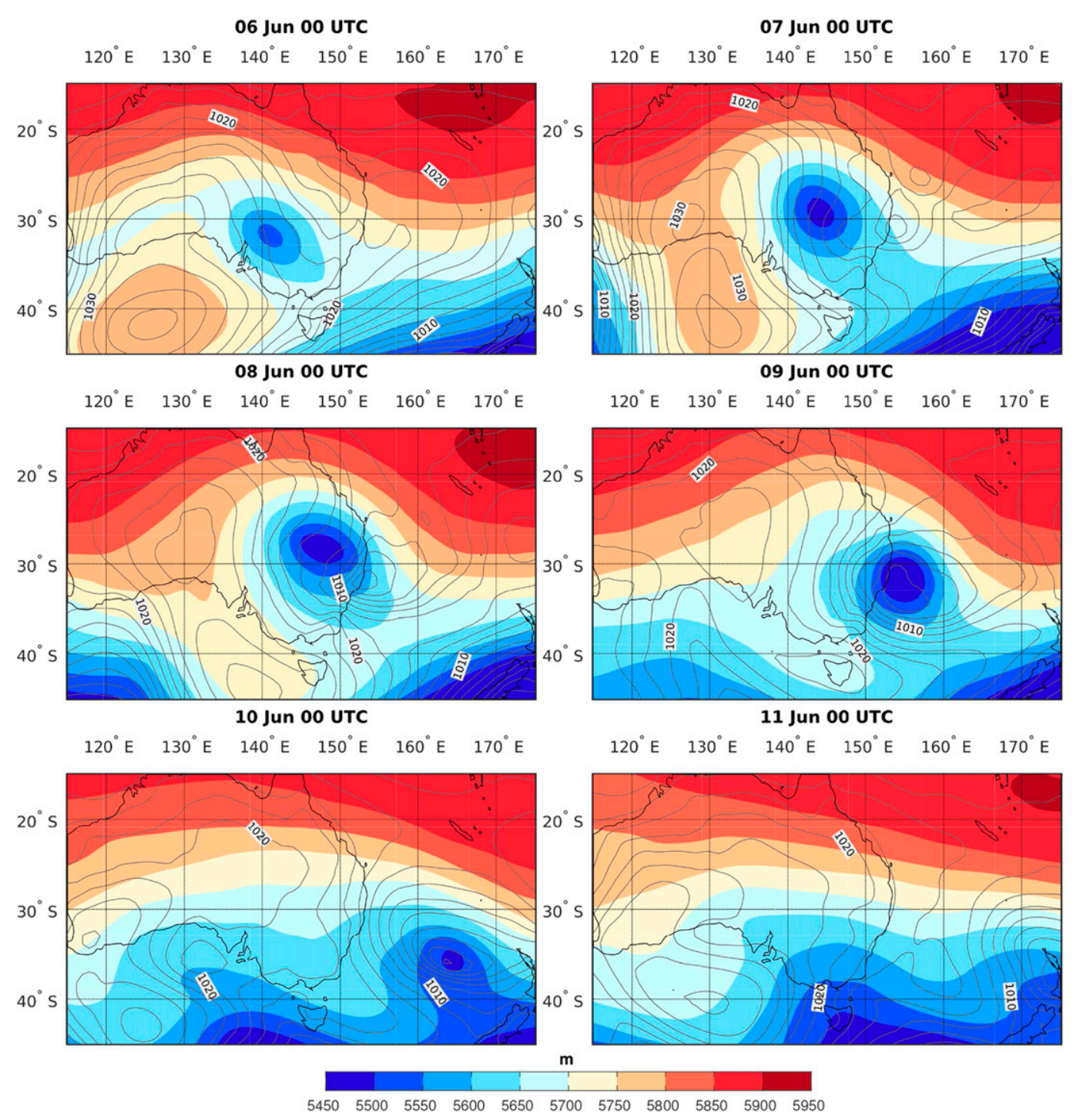

FIG. 4. As in Fig. 3, but for the Pasha Bulker.

indication of a relationship with lightning activity (as shown by the correlation coefficient $R=-0.46$ for the Duck and $R=-0.41$ for the Pasha Bulker) with more lightning activity for lower values of this parameter. The correlation between lightning and upper atmosphere thermal wind is weaker (correlation coefficient $R=-0.30$ for the Duck and $R=-0.43$ for the Pasha Bulker) with respect to the lower atmosphere. The lowertropospheric thermal symmetry measure, $B$, shows no clear indication of a relationship with lightning activity (correlation coefficient $R=0.17$ for the Duck and $R=-0.19$ for the Pasha Bulker). This seems to suggest that deep convective processes are not related to the cyclone vertical symmetry in the region around the threshold value $B=10$ for these two cases.
The energetics terms are calculated over all the grid points (both ocean and land) in a domain defined by the boundaries $25^{\circ}-50^{\circ} \mathrm{S}, 150^{\circ}-175^{\circ} \mathrm{E}$, as shown in Fig. 8 . The size of the domain is intended to be large enough to include the cyclone's formation and intensification regions, as well as small enough to avoid other synoptic weather features. Changes in the shape and extension of the domain were tested and their effect was found to be minor (not shown). The chosen domain differs from the one used in Pezza et al. (2014), since a focus of the current study is to select an optimal domain for the comparison of these two storms with a view toward potential future developments of this method for general application to many storms in this region (e.g., climatological investigations). 
a) $5^{\text {sn }}$ OOUTC $(0)$

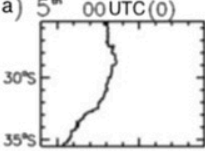

$6^{\text {*n }}$ OOUTC $(50)$

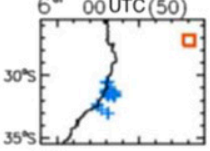

$7^{\text {th }}$ OOUTC (30)

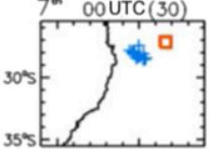

$8^{\text {m }}$ OOUTC $(0)$

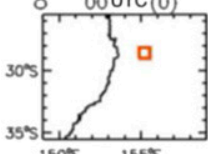

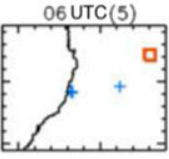

06 UTC(97)

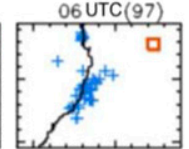

06 UTC (72)
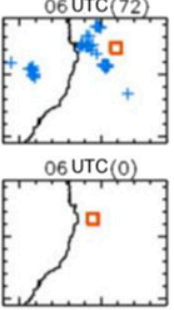
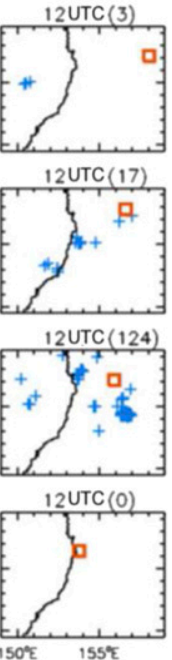

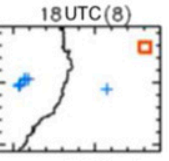

18 UTC (47)

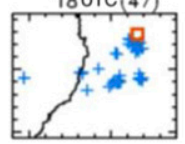

18 UTC (0)

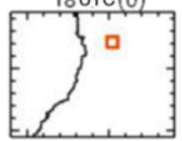

18 UTC (446)

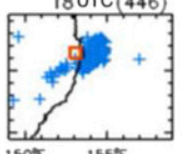

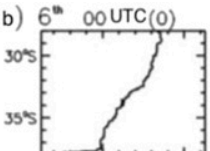
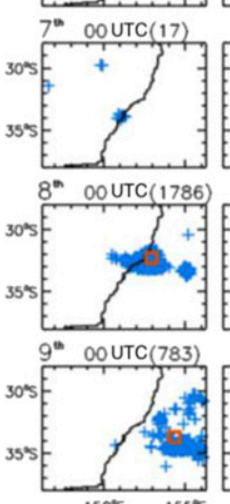

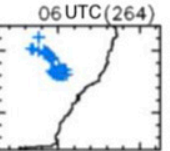

06 UTC (104)
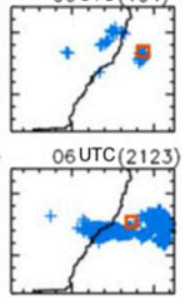

06 UTC (98)

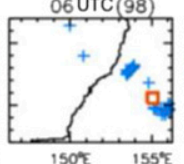

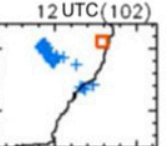

12 UTC (59)

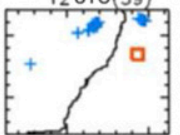

12 UTC (342)

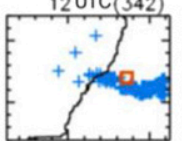

12 UTC (2)
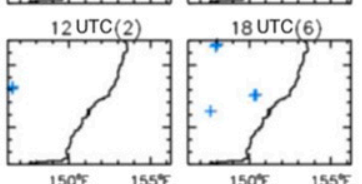

FIG. 5. The 6-hourly lightning strokes for (a) the Duck for 5-8 Mar 2001 and (b) the Pasha Bulker for 6-9 Jun 2007. UTC time and number of lightning strokes are indicated above each panel, with the lightning data representing all observations in the region shown within a 6-h period from the time listed. The available lightning data represent a lower bound of the actual lightning that occurred, given the unknown aspects of the commercial data provider's lightning sensor detection efficiency. Red squares indicate the storm center position as detected in ERA-Interim.

The time evolution of the energetics of the two storms is shown in Fig. 9. For both storms, there is a very clear signal in the energetics terms, characterized by a

significant departure from the background values, starting at the times of cyclone formation and persisting for the time the cyclone remains active within the

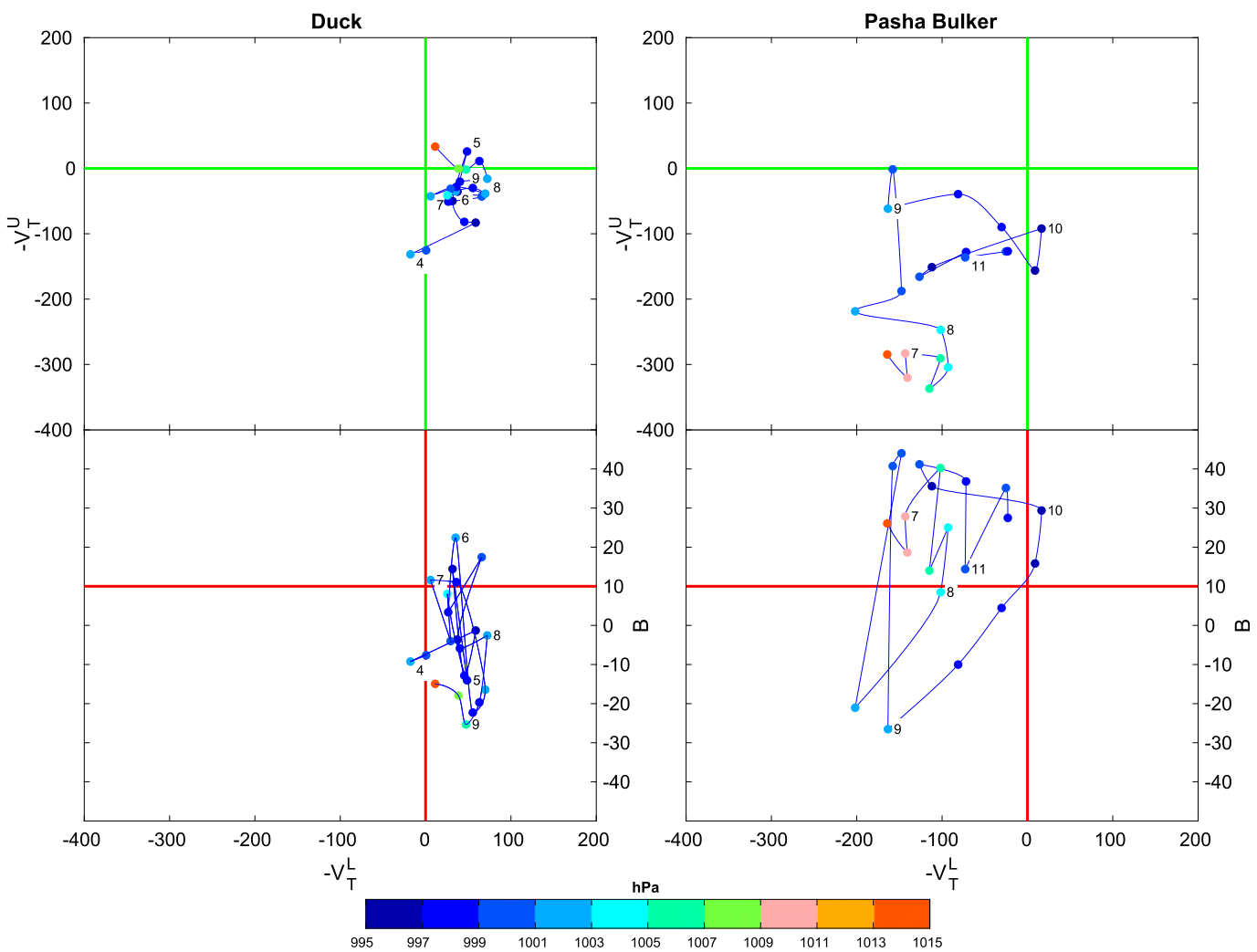

FIG. 6. Phase space plots for (left) the Duck and (right) the Pasha Bulker: (top) $-V_{T}^{L}$ and $-V_{T}^{U}$ and (bottom) $-V_{T}^{L}$ and $B$ parameter. Colored circles represent the values of mean sea level pressure minima as shown in the color scale. Text labels indicate the dates (for 0000 UTC times) in the month of March 2001 for the Duck and June 2007 for the Pasha Bulker. 

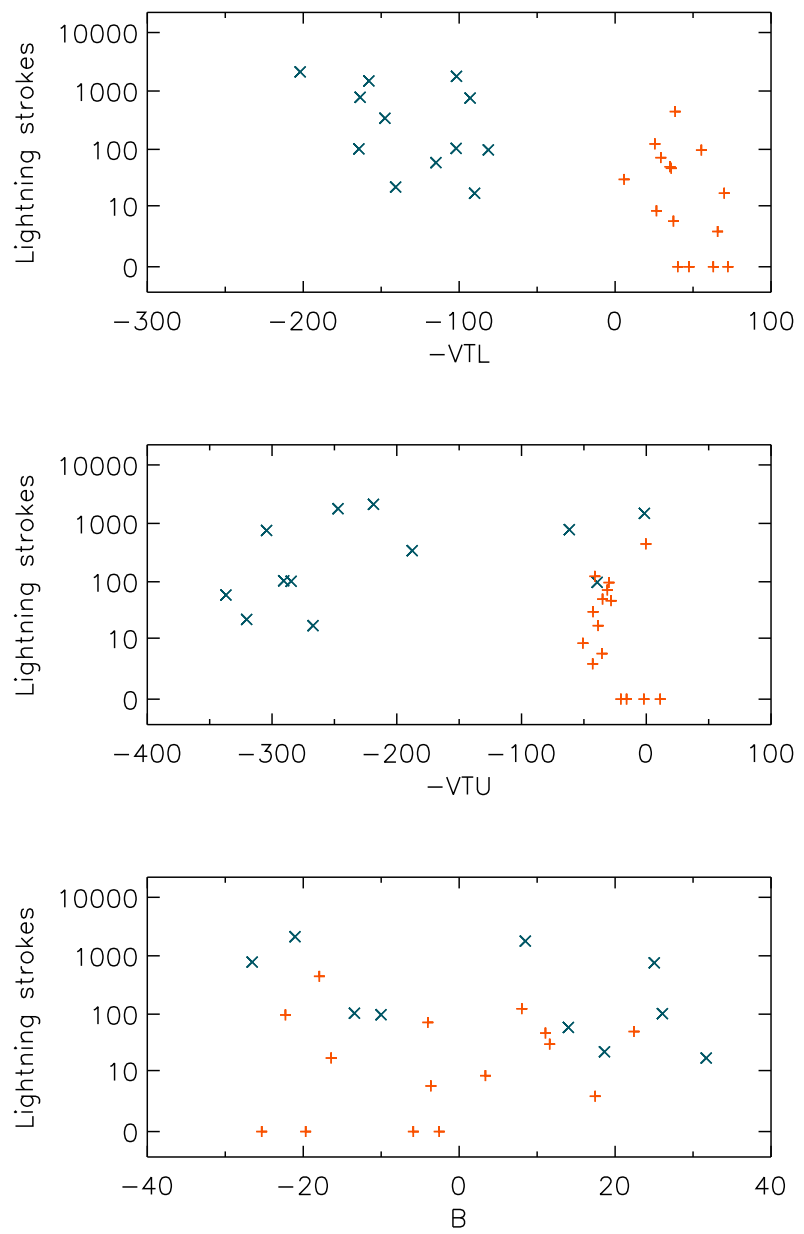

FIG. 7. Lightning stroke counts vs phase space parameters. This is shown for the Duck (orange) and the Pasha Bulker (blue) cases. The lightning counts are 6-hourly totals (for the periods centered on each ERA-Interim time step) within the time periods and regions shown in Fig. 5 for the two events. The $y$ axis uses a scaling based on the number of lightning strokes +1 , with the natural logarithm of this sum then calculated.

calculation box (3-9 March for the Duck and 7-11 June for the Pasha Bulker). The time series of the conversion terms for the Duck is characterized by a peak in the $C_{K}$ term approximately at the time of cyclogenesis (3 March). This is an indication of the role of barotropic processes in the storm formation. However, during most of the storm evolution, the magnitudes of the barotropic and baroclinic terms are comparable, consistent with the hybrid classification emerging from the phase space analysis for the Duck case. Finally, the landfall stage (8 March) is characterized by a peak in the $C_{Z}$ term. The strongest lighting activity is also observed during this phase. In the case of the Pasha Bulker storm, on the other hand, the first stage of storm intensification

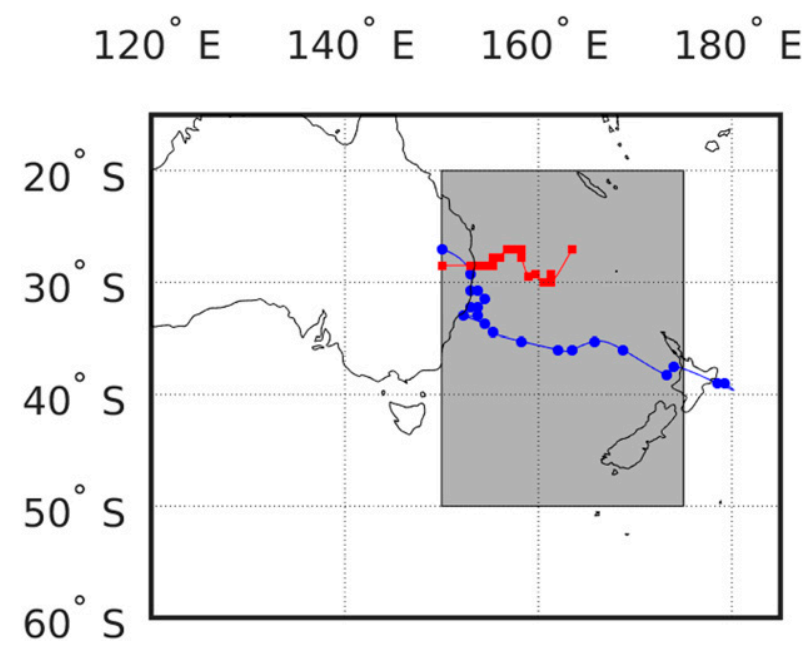

FIG. 8. Calculation domain for the energetics. The tracks of the Pasha Bulker (blue circles) and the Duck (red squares) are also shown for reference.

(8-9 June) is associated with a peak in the $C_{Z}$ term, and it is also associated with the strongest observed lighting activity. Around the stage of maximum deepening (10 June) the term $C_{Z}$ starts to decrease, while the two baroclinic terms $C_{A}$ and $C_{E}$ show a simultaneous peak. This is similar to the signature described in Black and Pezza (2013) for explosively deepening midlatitude cyclones. In this case, however, an additional feature is present [i.e., the (negative) peak of the $C_{K}$ term in addition to the peak of the baroclinic terms at the stage of maximum intensification]. This is consistent with the phase space analysis showing that the structure in this stage of the storm evolution becomes vertically aligned, and indicates that even though the Pasha Bulker was mostly a baroclinic-driven cyclone, barotropic processes might have been nonnegligible in the later stage of its evolution.

\section{c. Impact of atmospheric data resolution and source}

It is a relevant question whether the discussed phase space and energetics results are robust with respect to the choice of the atmospheric dataset used to conduct the analysis. To address this issue, we repeat some of the previous analysis using the NARCliM dataset instead of ERA-Interim. Not only does NARCliM have a different resolution from ERA-Interim, but it is also obtained employing different methods (i.e., using a regional climate model to derive higher-resolution fields from the underlying reanalysis data through dynamical downscaling); furthermore it is forced by a coarser large-scale dataset, the NCEP-NCAR reanalysis. This makes the case for a meaningful comparison, given these 

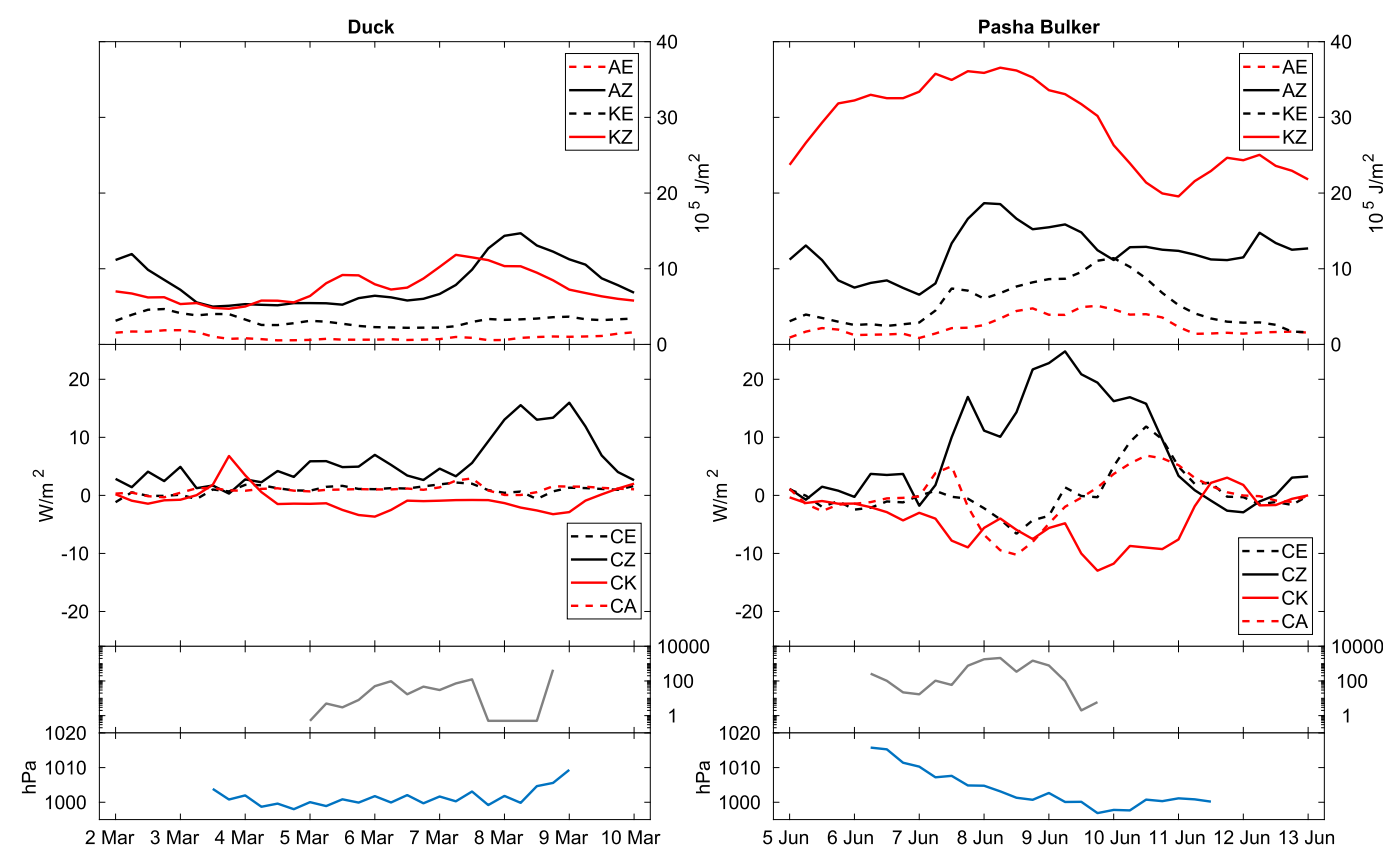

FIG. 9. Energetics of (left) the Duck and (right) the Pasha Bulker, as represented in ERA-Interim. (from top to bottom) Time series of the energy terms $\left(A_{Z}, A_{E}, K_{Z}\right.$, and $\left.K_{E}\right)$; time series of the energy conversion terms $\left(C_{K}, C_{Z}, C_{A}\right.$, and $C_{E}$ ); time series of 6-hourly lightning counts; and time series of cyclone's minimum mean sea level pressure.

significant differences. It has been shown (e.g., Cavicchia and von Storch 2012) that the properties of real-world storm cases in dynamical downscaling datasets can deviate significantly from the observations, because of the free dynamical evolution of the small scales introduced by the regional model, even though special provisions such as spectral nudging are usually undertaken to limit that. Furthermore, Mazza et al. (2017) have shown that phase space parameters can in some circumstances exhibit a sensitivity to perturbations in the forcing fields. The comparison is performed using the $50-\mathrm{km}$ resolution NARCliM simulations, since the regional model domain used in the $10-\mathrm{km}$ resolution simulations is smaller than the region used for the computation of cyclone energetics.

The cyclone tracks in the two datasets (Fig. 10) show some nonnegligible differences, diverging up to a few hundred kilometers. On the other hand, the evolution of the pressure minimum shows smaller deviations. As Fig. 11 shows, the phase space analysis is consistent for both storms with that obtained using ERA-Interim data. Figure 12 shows the results of the energetics analysis for the Duck and Pasha Bulker cyclones, derived from the NARCliM atmospheric fields. For the Pasha Bulker there is a remarkable similarity between the energetics terms computed from ERA-Interim and NARCliM. For the Duck, there is a difference of about $5 \mathrm{~W} \mathrm{~m}^{-2}$ in the amplitude of the $C_{Z}$ peak in the landfall phase of the cyclone. The occurrence time of the peaks of the different conversion terms and their relative magnitude, representative of the leading processes in the storm formation and evolution, are the same in the two datasets. Overall, the outcome of the comparison supports the conclusion that the employed methodology is robust and provides reliable results.

\section{Discussion and conclusions}

In the present work we showed the potential of a physically based classification approach of Australian ECLs, based on the synergy of cyclone phase space and cyclone energetics diagnostics. Two historical wellknown cyclone cases, representative of different storm typologies belonging to the broad set of ECLs, were examined to illustrate in detail such an approach.

On the one hand, the cyclone phase space parameters give indications of the internal structure of the storm. The three parameters summarize the information about the thermal structure of the cyclone and its degree of vertical symmetry. The use of the phase space parameters allows a classification of low pressure systems based on their predominant barotropic, baroclinic, or hybrid structure. The energetics diagnostics, on the other hand, describe the kind of processes taking place in the 
Duck

$120^{\circ} \mathrm{E} 130^{\circ} \mathrm{E} 140^{\circ} \mathrm{E} 150^{\circ} \mathrm{E} 160^{\circ} \mathrm{E} 170^{\circ} \mathrm{E} 180^{\circ} \mathrm{E}$

Pasha Bulker
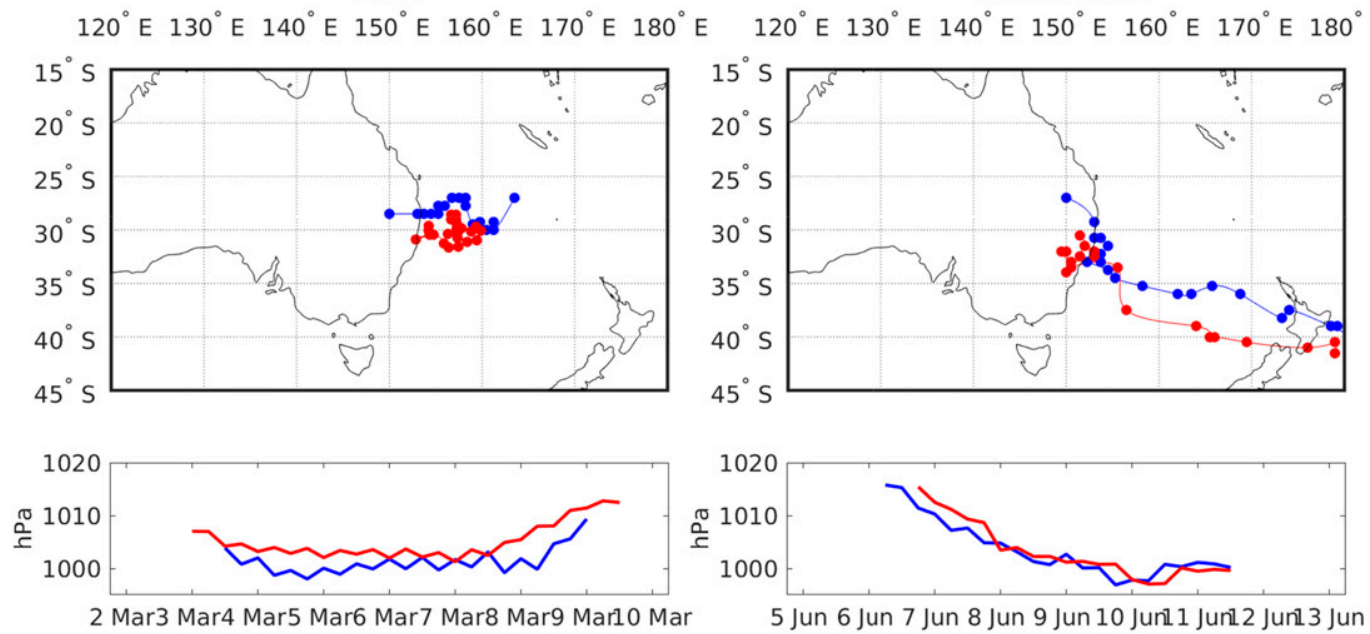

FIG. 10. Comparison of (left) the Duck and (right) the Pasha Bulker as represented respectively by ERA-Interim (blue lines and dots) and NARCliM (red lines and dots). (top) Cyclone track. (bottom) Time series of mean sea level pressure minimum.

large-scale environment surrounding the storm. While not directly related to the storm itself, such diagnostics provide nonetheless relevant information concerning the energy content of the atmosphere feeding the cyclone, and the conversions between different energy components. Such information is complementary to that obtained from the phase space analysis in determining the barotropic and baroclinic contributions to the storm intensification.

The outcome of our analysis shows that the Duck and the Pasha Bulker, even though they are both included in the broad ECL set, are two different kinds of storms. The thermal structure of the Duck classifies it as a hybrid cyclone. The barotropic and baroclinic energy conversion terms have a comparable magnitude during the storm formation and evolution, reinforcing the outcome of the phase space analysis. The Pasha Bulker on the other hand shows the typical thermal structure of a baroclinic cyclone. Also in this case, the energetics signature supports the phase space diagnostics, being dominated by the baroclinic terms during the storm formation and deepening.

Both of these storms formed in broadscale environments that were relatively unstable convectively, as evident from the observed lightning in surrounding regions during the storms development. Larger values of the $C_{z}$ term for the energetics analysis showed some indication of being associated with stronger lightning activity, with relatively little clear indication of a relationship for the other phase space parameters. Large values of $C_{z}$ were observed during the middle of the Pasha Bulkers lifetime in a phase of intensification (i.e., deepening central pressure), as well as for the Duck around the time of landfall, with intense convective processes apparent in both cases during these times (as evident from the lightning activity). While noting that these results are only based on two cases, it is hypothesized that larger vertical temperature gradients could enhance the convective instability of the environment, leading to stronger kinetic energy of the storm (i.e., $C_{z}$ represents a growth of zonal kinetic energy $K_{z}$, at the expense of zonal available potential energy $A_{z}$ ).

The approach based on the phase space and energetics analysis of ECLs will be systematically applied to multidecadal climatologies of storms derived from reanalysis datasets, in order to define an ECL classification based on the physical processes leading to their formation and intensification. This classification scheme could also be investigated for use in classifying cyclones in other subtropical regions.

Moreover, the approach illustrated here is expected to lead to progress in the interpretation of projections of ECL occurrence. The comparison of the energetics signatures of ECLs in historical and future climate model simulations will help to shed light on the diverse response of different classes of storms to changes in the state of climate, according to the respective role played by barotropic and baroclinic processes in their formation and intensification. The results of this study also show that dynamically downscaled simulations correctly reproduce 

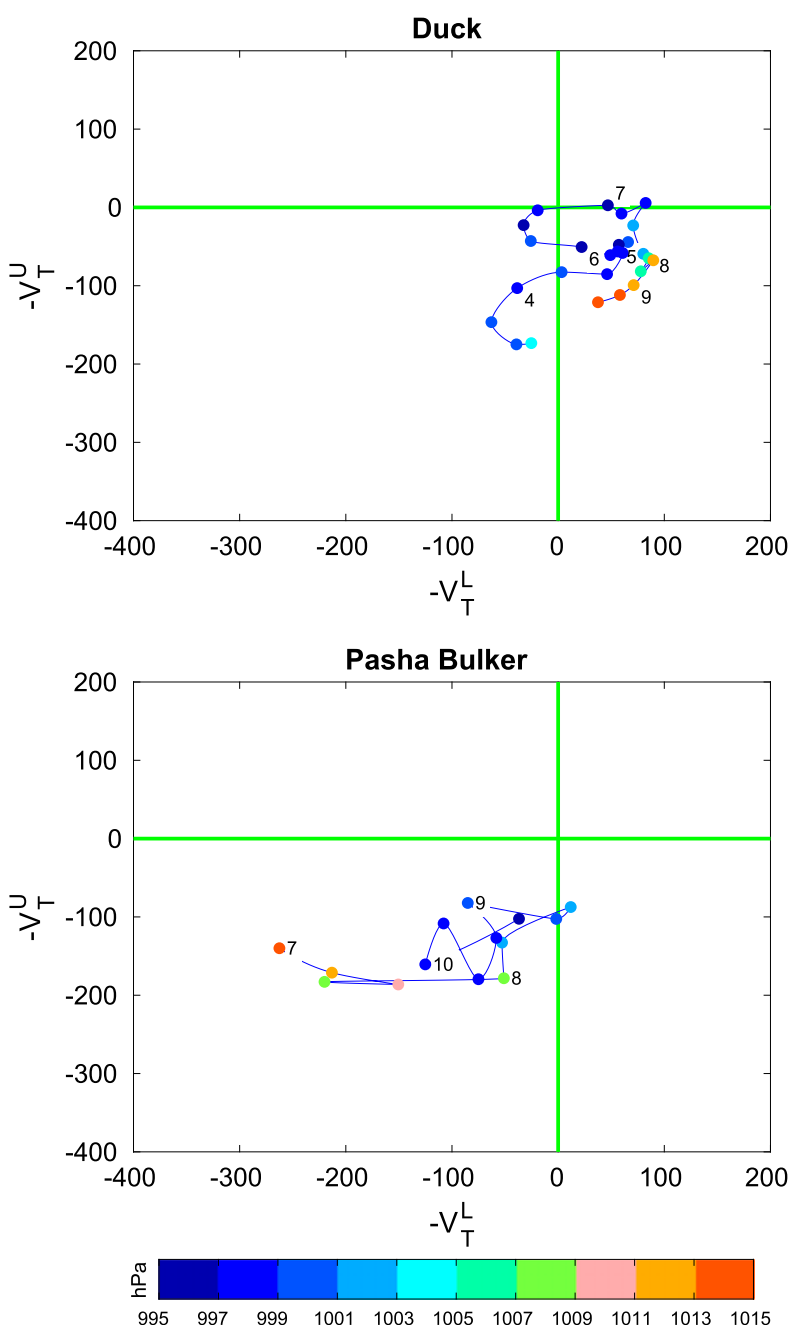

FIG. 11. Phase space plot for (top) the Duck and (bottom) the Pasha Bulker as represented in NARCliM: $-V_{T}^{L}$ and $-V_{T}^{U}$. Colored circles represent the values of mean sea level pressure minima as shown in the color scale. Text labels indicate the dates (for 0000 UTC times) in the month of March 2001 for the Duck and June 2007 for the Pasha Bulker.

the different diagnostics, and thus have a good potential for further climate change analysis. Finally, the methodology described here could help improve the predictability of ECLs impacts. In particular, indications of a stronger than usual storm intensification could be derived from the energetics diagnostics, providing additional guidance to complement that provided by numerical model simulations of storm evolution.

Acknowledgments. This research was supported through funding from the Earth System and Climate Change Hub of the Australian government's National Environmental Science Programme. The authors acknowledge Jason Evans for help in accessing the NARCliM data. The authors thank
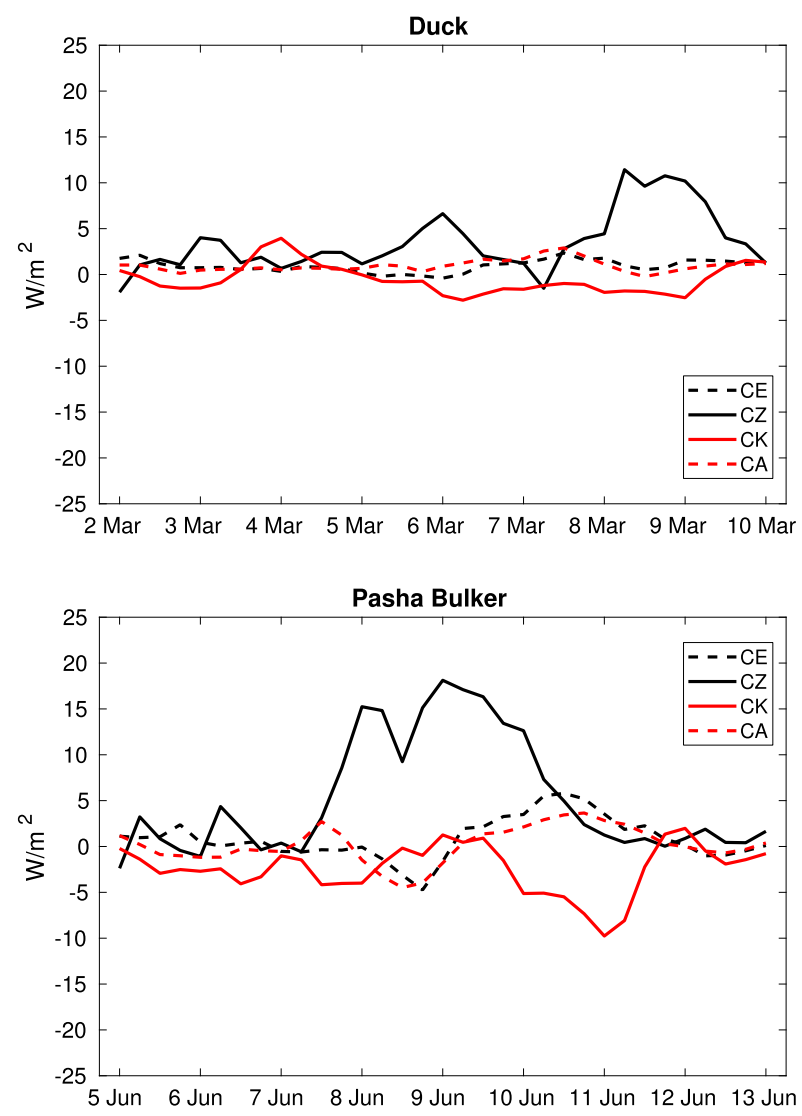

FIG. 12. Energetics of (top) the Duck and (bottom) the Pasha Bulker as represented in NARCliM: time series of the energy conversion terms $\left(C_{K}, C_{Z}, C_{A}\right.$, and $\left.C_{E}\right)$.

Acacia Pepler, Kevin Tory, and two anonymous reviewers for their constructive comments on earlier versions of this manuscript.

\section{REFERENCES}

Black, M. T., and A. B. Pezza, 2013: A universal, broad-environment energy conversion signature of explosive cyclones. Geophys. Res. Lett., 40, 452-457, https://doi.org/10.1002/grl.50114.

Boer, G., and S. Lambert, 2008: The energy cycle in atmospheric models. Climate Dyn., 30, 371-390, https://doi.org/10.1007/ s00382-007-0303-4.

Browning, S. A., and I. D. Goodwin, 2013: Large-scale influences on the evolution of winter subtropical maritime cyclones affecting Australia's east coast. Mon. Wea. Rev., 141, 24162431, https://doi.org/10.1175/MWR-D-12-00312.1.

Caruso, S. J., and S. Businger, 2006: Subtropical cyclogenesis over the central North Pacific. Wea. Forecasting, 21, 193-205, https://doi.org/10.1175/WAF914.1.

Cavicchia, L., and H. von Storch, 2012: The simulation of medicanes in a high-resolution regional climate model. Climate Dyn., 39, 2273-2290, https://doi.org/10.1007/s00382-011-1220-0.

, - - and S. Gualdi, 2014a: A long-term climatology of medicanes. Climate Dyn., 43, 1183-1195, https://doi.org/10.1007/ s00382-013-1893-7. 
,-- , and $-2014 \mathrm{~b}$ : Mediterranean tropical-like cyclones in present and future climate. J. Climate, 27, 7493-7501, https://doi.org/10.1175/JCLI-D-14-00339.1.

Chambers, C. R., G. B. Brassington, I. Simmonds, and K. Walsh, 2014: Precipitation changes due to the introduction of eddy-resolved sea surface temperatures into simulations of the Pasha Bulker Australian east coast low of June 2007. Meteor. Atmos. Phys., 125, 1-15, https://doi.org/10.1007/s00703-014-0318-4.

,,-- K. Walsh, and I. Simmonds, 2015: Sensitivity of the distribution of thunderstorms to sea surface temperatures in four Australian east coast lows. Meteor. Atmos. Phys., 127, 499-517, https://doi.org/10.1007/s00703-015-0382-4.

Cummins, K. L., and M. J. Murphy, 2009: An overview of lightning locating systems: History, techniques, and data uses, with an indepth look at the US NLDN. IEEE Trans. Electromagn. Compat., 51, 499-518, https://doi.org/10.1109/TEMC.2009.2023450.

Davis, C. A., and L. F. Bosart, 2003: Baroclinically induced tropical cyclogenesis. Mon. Wea. Rev., 131, 2730-2747, https://doi.org/ 10.1175/1520-0493(2003)131<2730:BITC > 2.0.CO;2.

— , and 2004: The TT problem: Forecasting the tropical transition of cyclones. Bull. Amer. Meteor. Soc., 85, 1657-1662, https://doi.org/10.1175/BAMS-85-11-1657.

Dee, D., and Coauthors, 2011: The ERA-Interim reanalysis: Configuration and performance of the data assimilation system. Quart. J. Roy. Meteor. Soc., 137, 553-597, https://doi.org/ 10.1002/qj.828.

Di Luca, A., J. P. Evans, A. S. Pepler, L. Alexander, and D. Argüeso, 2015: Resolution sensitivity of cyclone climatology over eastern Australia using six reanalysis products. J. Climate, 28, 9530-9549, https://doi.org/10.1175/JCLI-D-14-00645.1.

,,,--- , and,- 2016 : Evaluating the representation of Australian east coast lows in a regional climate model ensemble. J. South. Hemisphere Earth Syst. Sci., 66, 108-124, https://doi.org/10.22499/3.6002.003.

Dias Pinto, J. R., and R. P. da Rocha, 2011: The energy cycle and structural evolution of cyclones over southeastern South America in three case studies. J. Geophys. Res. Atmos., 116, D14112, https://doi.org/10.1029/2011JD016217.

— M. S. Reboita, and R. P. da Rocha, 2013: Synoptic and dynamical analysis of subtropical cyclone Anita (2010) and its potential for tropical transition over the South Atlantic Ocean. J. Geophys. Res. Atmos., 118, $10870-10883$, https:// doi.org/10.1002/jgrd.50830.

Dowdy, A. J., and Y. Kuleshov, 2014: Climatology of lightning activity in Australia: Spatial and seasonal variability. Aust. Meteor. Ocean J., 6, 9-14.

— , G. A. Mills, and B. Timbal, 2011: Large-scale indicators of Australian East Coast Lows and associated extreme weather events. Centre for Australia Weather and Climate Research Tech. Rep. 37, 104 pp.

,$- \ldots$, and - 2013a: Large-scale diagnostics of extratropical cyclogenesis in eastern Australia. Int. J. Climatol., 33, 2318-2327, https://doi.org/10.1002/joc.3599.

,,--- , and Y. Wang, 2013b: Changes in the risk of extratropical cyclones in eastern Australia. J. Climate, 26, 14031417, https://doi.org/10.1175/JCLI-D-12-00192.1.

Evans, J. L., and A. Braun, 2012: A climatology of subtropical cyclones in the South Atlantic. J. Climate, 25, 7328-7340, https://doi.org/10.1175/JCLI-D-11-00212.1.

Evans, J. P., F. Ji, C. Lee, P. Smith, D. Argüeso, and L. Fita, 2014: Design of a regional climate modelling projection ensemble experiment-NARCliM. Geosci. Model Dev., 7, 621-629, https://doi.org/10.5194/gmd-7-621-2014.
Garde, L. A., A. B. Pezza, and J. A. Tristram Bye, 2010: Tropical transition of the 2001 Australian Duck. Mon. Wea. Rev., 138, 2038-2057, https://doi.org/10.1175/2009MWR3220.1.

Gozzo, L. F., R. P. da Rocha, M. S. Reboita, and S. Sugahara, 2014: Subtropical cyclones over the southwestern South Atlantic: Climatological aspects and case study. J. Climate, 27, 8543-8562, https://doi.org/10.1175/JCLI-D-14-00149.1.

Guishard, M. P., J. L. Evans, and R. E. Hart, 2009: Atlantic subtropical storms. Part II: Climatology. J. Climate, 22, 3574-3594, https://doi.org/10.1175/2008JCLI2346.1.

Hart, R. E., 2003: A cyclone phase space derived from thermal wind and thermal asymmetry. Mon. Wea. Rev., 131, 585-616, https:// doi.org/10.1175/1520-0493(2003)131<0585:ACPSDF>2.0.CO;2.

Holland, G. J., A. H. Lynch, and L. M. Leslie, 1987: Australian east-coast cyclones. Part I: Synoptic overview and case study. Mon. Wea. Rev., 115, 3024-3036, https://doi.org/10.1175/ 1520-0493(1987)115<3024:AECCPI>2.0.CO;2.

Hopkins, L. C., and G. J. Holland, 1997: Australian heavy-rain days and associated east coast cyclones: 1958-92. J. Climate, 10, 621-635, https://doi.org/10.1175/1520-0442(1997)010<0621: AHRDAA $>2.0 . \mathrm{CO} ; 2$.

Kalnay, E., and Coauthors, 1996: The NCEP/NCAR 40-Year Reanalysis Project. Bull. Amer. Meteor. Soc., 77, 437-471, https:// doi.org/10.1175/1520-0477(1996)077<0437:TNYRP>2.0.CO;2.

Kuleshov, Y., D. Mackerras, and M. Darveniza, 2006: Spatial distribution and frequency of lightning activity and lightning flash density maps for Australia. J. Geophys. Res., 111, D19105, https://doi.org/10.1029/2005JD006982.

Lorenz, E. N., 1955: Available potential energy and the maintenance of the general circulation. Tellus, 7, 157-167, https:// doi.org/10.3402/tellusa.v7i2.8796.

Mauk, R. G., and J. S. Hobgood, 2012: Tropical cyclone formation in environments with cool SST and high wind shear over the northeastern Atlantic Ocean. Wea. Forecasting, 27, 14331448, https://doi.org/10.1175/WAF-D-11-00048.1.

Mazza, E., U. Ulbrich, and R. Klein, 2017: The tropical transition of the October 1996 medicane in the western Mediterranean Sea: A warm seclusion event. Mon. Wea. Rev., 145, 2575-2595, https://doi.org/10.1175/MWR-D-16-0474.1.

McTaggart-Cowan, R., G. D. Deane, L. F. Bosart, C. A. Davis, and T. J. Galarneau Jr., 2008: Climatology of tropical cyclogenesis in the North Atlantic (1948-2004). Mon. Wea. Rev., 136, 12841304, https://doi.org/10.1175/2007MWR2245.1.

Michalakes, J., S. Chen, J. Dudhia, L. Hart, J. Klemp, J. Middlecoff, and W. Skamarock, 2001: Development of a next generation regional weather research and forecast model. Developments in Teracomputing: Proceedings of the Ninth ECMWF Workshop on the Use of High Performance Computing in Meteorology, W. Zwieflhofer and N. Kreitz, Eds., Vol. 1, World Scientific, 269-276.

Miglietta, M., S. Laviola, A. Malvaldi, D. Conte, V. Levizzani, and C. Price, 2013a: Analysis of tropical-like cyclones over the Mediterranean Sea through a combined modeling and satellite approach. Geophys. Res. Lett., 40, 2400-2405, https://doi.org/ 10.1002/grl.50432.

,,,,----- , and,$- 2013 \mathrm{~b}$ : Analysis of tropicallike cyclones over the Mediterranean Sea through a combined modeling and satellite approach. Geophys. Res. Lett., 40, 2400-2405, https://doi.org/10.1002/grl.50432.

Mills, G. A., R. Webb, N. E. Davidson, J. Kepert, A. Seed, and D. Abbs, 2010: The Pasha Bulker east coast low of 8 June 2007. Centre for Australian Weather and Climate Research Tech. Rep., 62 pp. 
Murray, R. J., and I. Simmonds, 1991: A numerical scheme for tracking cyclone centres from digital data. Aust. Meteor. Mag., 39, 155-166.

Otkin, J. A., and J. E. Martin, 2004: A synoptic climatology of the subtropical kona storm. Mon. Wea. Rev., 132, 1502-1517, https:// doi.org/10.1175/1520-0493(2004)132<1502:ASCOTS>2.0.CO;2.

Pepler, A. S., and A. Coutts-Smith, 2013: A new, objective, database of East Coast Lows. Aust. Meteor. Ocean J., 63, 461-472, https://doi.org/10.22499/2.6304.001.

—, A. Di Luca, F. Ji, L. V. Alexander, J. P. Evans, and S. C. Sherwood, 2015: Impact of identification method on the inferred characteristics and variability of Australian east coast lows. Mon. Wea. Rev., 143, 864-877, https://doi.org/10.1175/ MWR-D-14-00188.1.

,,,,----- , and,- 2016 : Projected changes in east Australian midlatitude cyclones during the 21st century. Geophys. Res. Lett., 43, 334-340, https://doi.org/10.1002/ 2015 GL067267.

— — - and J. P. Evans, 2018: Independently assessing the representation of midlatitude cyclones in high-resolution reanalyses using satellite observed winds. Int. J. Climatol., $\mathbf{3 8}$, 1314-1327, https://doi.org/10.1002/joc.5245.

Pezza, A. B., L. A. Garde, J. A. P. Veiga, and I. Simmonds, 2014: Large scale features and energetics of the hybrid subtropical low Duck over the Tasman Sea. Climate Dyn., 42, 453-466, https://doi.org/10.1007/s00382-013-1688-x.

Price, C., M. Asfur, and Y. Yair, 2009: Maximum hurricane intensity preceded by increase in lightning frequency. Nat. Geosci., 2, 329-332, https://doi.org/10.1038/ngeo477.
Qi, L., L. Leslie, and M. Speer, 2006: Climatology of cyclones over the southwest Pacific: 1992-2001. Meteor. Atmos. Phys., 91, 201-209, https://doi.org/10.1007/s00703-005-0149-4.

Rakov, V. A., and M. A. Uman, 2003: Lightning: Physics and Effects. Cambridge University Press, $687 \mathrm{pp}$.

Raymond, D. J., and S. L. Sessions, 2007: Evolution of convection during tropical cyclogenesis. Geophys. Res. Lett., 34, L06811, https://doi.org/10.1029/2006GL028607.

Speer, M. S., P. Wiles, A. Pepler, 2009: Low pressure systems off the New South Wales coast and associated hazardous weather: Establishment of a database. Aust. Meteor. Ocean J., 58, 29-39, https://doi.org/10.22499/2.5801.004.

Veiga, J. A. P., and T. Ambrizzi, 2013: A global and hemispherical analysis of the Lorenz energetics based on the representative concentration pathways used in CMIP5. Adv. Meteor., 2013, 485047, https://doi.org/10.1155/2013/485047.

, A. B. Pezza, I. Simmonds, and P. L. Silva Dias, 2008: An analysis of the environmental energetics associated with the transition of the first South Atlantic hurricane. Geophys. Res. Lett., 35, L15806, https://doi.org/10.1029/ 2008GL034511.

Walsh, K., F. Giorgi, and E. Coppola, 2014: Mediterranean warmcore cyclones in a warmer world. Climate Dyn., 42, 1053-1066, https://doi.org/10.1007/s00382-013-1723-y.

Yanase, W., H. Niino, K. Hodges, and N. Kitabatake, 2014: Parameter spaces of environmental fields responsible for cyclone development from tropics to extratropics. J. Climate, 27, 652-671, https://doi.org/10.1175/JCLI-D-1300153.1. 